\title{
Evaluating Strategies for Ranching in the 21st Century: Successfully Managing Rangeland for Wildifie and Livestock
}

\section{By Austin Anderson and Kimberly C. McCuistion}

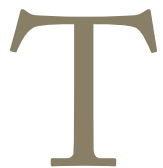

he goal to successfully manage rangelands for both wildlife and livestock production is not new to the 21st Century. In 1878, John Wesley Powell, the famous explorer and surveyor of the western United States, challenged a growing nation to find ways to accomplish human settlement and its associated livestock production through careful management of the rangeland resources (including wildlife) west of the hundredth meridian. ${ }^{1}$ Almost a hundred years ago, the renowned wildlife conservationist and cattle rancher Caesar Kleberg of King Ranch instituted not only daily bag limits and seasonal harvest quotas for many wildlife species, but he also developed habitat management plans for the rangelands of the vast ranch while continuing cattle production. ${ }^{2} \mathrm{~A}$ stewardship ethic for all of the resources found on rangelands has been reflected in the mission statement of the Society for Range Management for its entire 60-year history. Today, from Canada through Mexico and across the west, there are countless examples of topnotch ranchers and rangeland managers who have found ways to successfully graze livestock while preserving and enhancing wildlife resources. Currently, and for the first time in the long history of range management, the economic benefits to ranchers from wildlife management are substantial, sometimes equaling or even exceeding revenues from livestock production.

With opportunity comes not only risk but also responsibility. Managing rangelands for both wildlife and livestock requires commitment, knowledge, and enhanced management skills. The following is a review of the literature concerning the management of rangeland habitat for upland game birds and large wild ungulates in conjunction with cattle grazing. Topics include livestock grazing factors such as stocking rate, grazing systems, fire, deferment, rest, utilization, and range condition and their impact on wildlife species that currently provide major economic opportunities for ranchers. Managing rangeland for both wildlife and cattle is a strategy worthy of careful consideration for ranch managers in the 21 st Century.

\section{Upland Game Birds}

When developing a management plan to maintain or improve wildlife habitat in conjunction with a livestock operation, it is important to understand the habitat requirements of the species of interest and how they are affected by various management practices. Studies involving specific grazing management systems and their impacts on upland game birds have produced variable results. Habitat requirements vary from species to species; therefore, management methods and grazing systems must vary as well. In general, rest-rotation and deferred-rotation grazing systems work well for most upland game birds because they allow for periods of reduced disturbance during critical lifecycle stages. See Table 1 for general grazing management guidelines. The following discussion provides some information on a few of these species and some grazing management strategies that are beneficial for habitat management.

\section{Sage Grouse}

The habitat needs of sage grouse can vary depending on the stage of its life cycle. ${ }^{3}$ Tall grasses and medium-height shrubs are important for cover and nesting. Adequate amounts of forbs and insects are needed for food and brood rearing, as is access to riparian areas for late-season forage. ${ }^{3}$

Sage grouse habitat management on public lands has become a much-debated issue. Research has shown that a 


\section{Table 1. General grazing management guide- lines: upland game birds}

1. Light to moderate stocking rate

- $30 \%-50 \%$ utilization

- Influenced by site productivity

2. Maintain flexible stocking rate

3. Deferred or rest-rotation grazing system

4. Proper timing of grazing

- Avoid disturbances during critical stages such as nesting

5. Closely monitor riparian areas to prevent overuse

properly designed and managed grazing plan can maintain and improve sage grouse habitat. ${ }^{4}$ Light to moderate grazing (30\%-50\% utilization) can increase forb quality and quantity. Grazing delays forb maturation and extends availability of high quality forage throughout the season. A light to moderate stocking rate can help maintain the grassy understory used by the sage grouse for cover while controlling the sagebrush that is needed for nesting. ${ }^{3}$ In contrast, a heavy stocking rate can cause the grassy understory to be overutilized, allowing the sagebrush to thicken. This can cause other grass species to be eliminated, thus reducing the diversity of certain plant populations needed for sage grouse habitat.

The time at which grazing occurs and the duration of grazing are the next most important factors to consider when managing sage grouse habitat. ${ }^{4}$ Forage species in sagebrush habitats are predominately cool-season plants. These plants can be vulnerable to stress during late spring and early summer due to growth and low energy levels. Deferred grazing until mid- to late summer, fall, or winter is usually compatible with maintaining herbaceous species in sagebrush communities. ${ }^{3} \mathrm{~A}$ deferral of grazing also benefits the sage grouse by reducing conflict between grazing livestock and sage grouse during breeding and nesting season. The duration of grazing should be limited to give forage adequate rest and time to recover. Sage grouse forage in riparian areas during the late growing season. These areas can be vulnerable during late summer and can be damaged by excessive grazing. Light to moderate grazing of these areas in the spring or early summer will allow these areas time to recover.

No single grazing system is best suited for managing sage grouse habitat. Each system has benefits as well as weaknesses. Ecological sites and regions have unique characteristics such that a grazing system appropriate in one area might not be for another. Several grazing systems can be applied to a single operation in order to make full use of the resources that are available. The most important thing

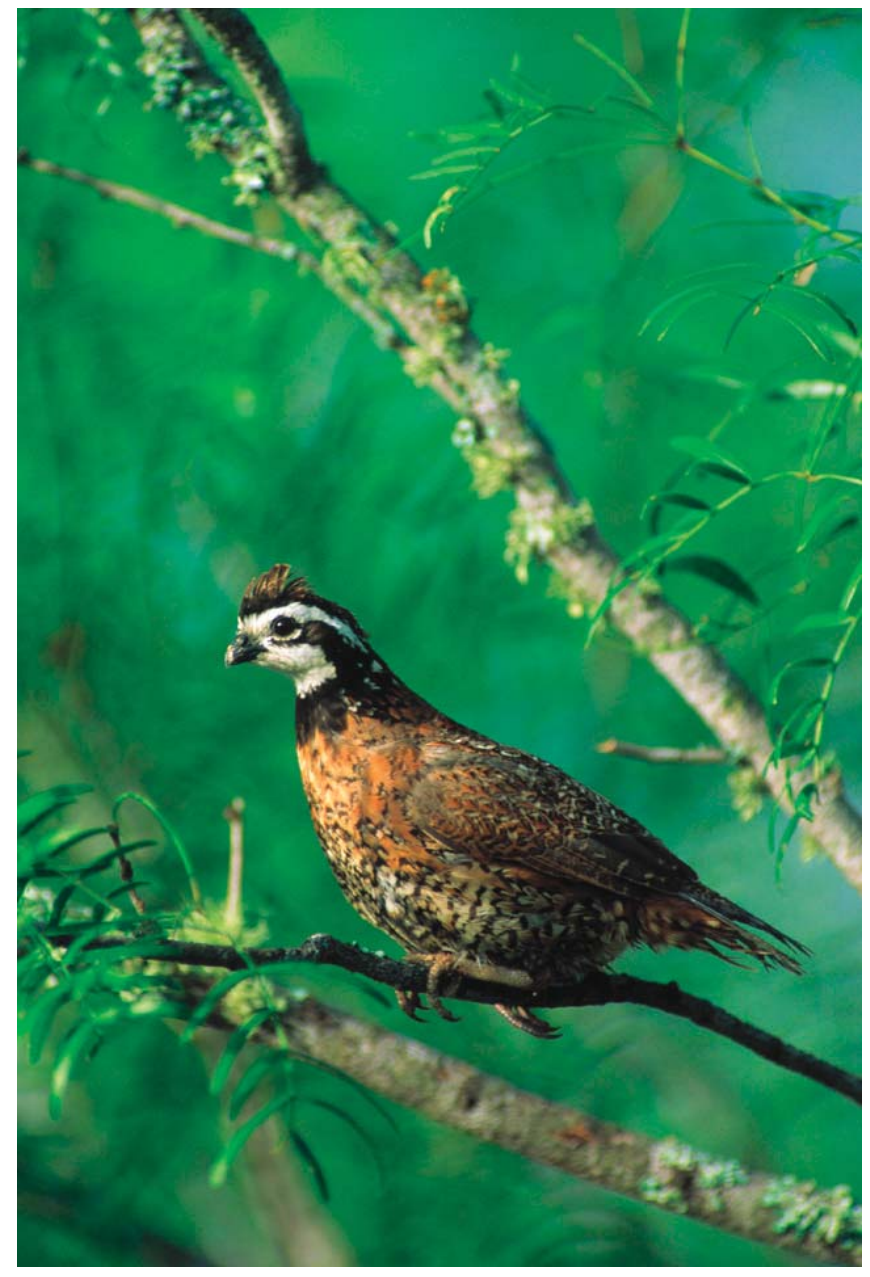

to keep in mind is that grazing management needs to be flexible and specifically designed for each management area.

\section{Bobwhite Quail}

Bobwhite quail are an important game bird species, particularly in South Texas. Bobwhite quail require various plant successional stages in order to meet their needs for food and cover. A large portion of the bobwhite diet is from forbs that produce large seeds that are high in energy. These types of forbs are often present in the early successional stages of plant communities. Insects also provide a large portion of the bobwhite's diet and are an important source of protein. Bobwhites prefer open or bare areas for foraging but also need patches of tall grass interspersed with open areas for cover and nesting.

The most important requirement for managing bobwhite habitat is flexibility in stocking rate. Higher stocking rates benefit quail on highly productive range sites because cattle consume and trample thick stands of forage and provide open areas. ${ }^{5}$ Light to moderate stocking rates are more suited to less productive rangeland to preserve adequate cover and range condition. ${ }^{5}$ The amount of precipitation 
also affects stocking rate for optimal bobwhite populations. Flexible stocking allows a rancher to increase stocking rates in periods of high rainfall and to decrease them during periods of low precipitation or drought.

The type of grazing system that is used is not as important if a proper stocking rate is applied for a particular situation. ${ }^{5}$ A study in South Texas concluded that sites receiving a short-duration grazing treatment experienced decreased ground litter accumulations, thereby increasing herb species and forb cover. ${ }^{6}$ Another study concluded bobwhite quail benefited more from a high-intensity/ low-frequency system than a continuous or Merrill threeherd/four-pasture system. ${ }^{7}$ High-intensity/low-frequency and short-duration grazing systems also have been shown to benefit quail in wetter areas. ${ }^{5}$ In drier areas, a rotational system can benefit quail, compared to a continuous grazing system, by maintaining a higher range condition necessary for low-producing range sites. ${ }^{5}$

Brush management is also an important consideration for maintaining or improving bobwhite quail habitat. Quality bobwhite quail habitat contains some shrubby vegetation as well as trees. Bobwhites are not adapted to thick stands of brush. Dense brush can reduce plant diversity and inhibit growth of grasses and forbs. Tall, thick, old-growth grass and ground litter can restrict quail movement and reduce bare ground needed for feeding. ${ }^{5}$ Prescribed burning in conjunction with controlled grazing is an effective way to open areas for increased movement and to reduce ground litter. December is the best month to burn to avoid killing forbs. ${ }^{5}$ Burning can make insects and seeds more available to quail by opening up the canopy of herbaceous vegetation. ${ }^{5}$ Burning should be done in patches to provide unburned areas for continual cover for the quail.

\section{Wild Turkeys}

As with other wildlife species, wild turkeys require food, water, and cover as their basic habitat requirements. It follows, then, that providing suitable habitat for wild turkeys requires maintenance or improvement of food, water, and cover. Turkeys utilize a variety of food sources, including insects, grasses, forbs, and browse. A major food source during spring and summer includes insects such as grasshoppers and beetles. Fruit from browse and various shrubs provide much of the fall diets for wild turkeys. Turkeys eat leaves and seeds from forbs and grasses during winter. Wild turkeys also forage on agricultural crops such as wheat and oats when available.

Water availability is also an important aspect of good wild turkey habitat. Sources of standing water should be no more than two miles apart. Research has shown that turkey populations have increased as a result of livestock water development such as dirt tanks and troughs. ${ }^{8}$ A water source is important for nesting, because most nests are located within a mile of water.

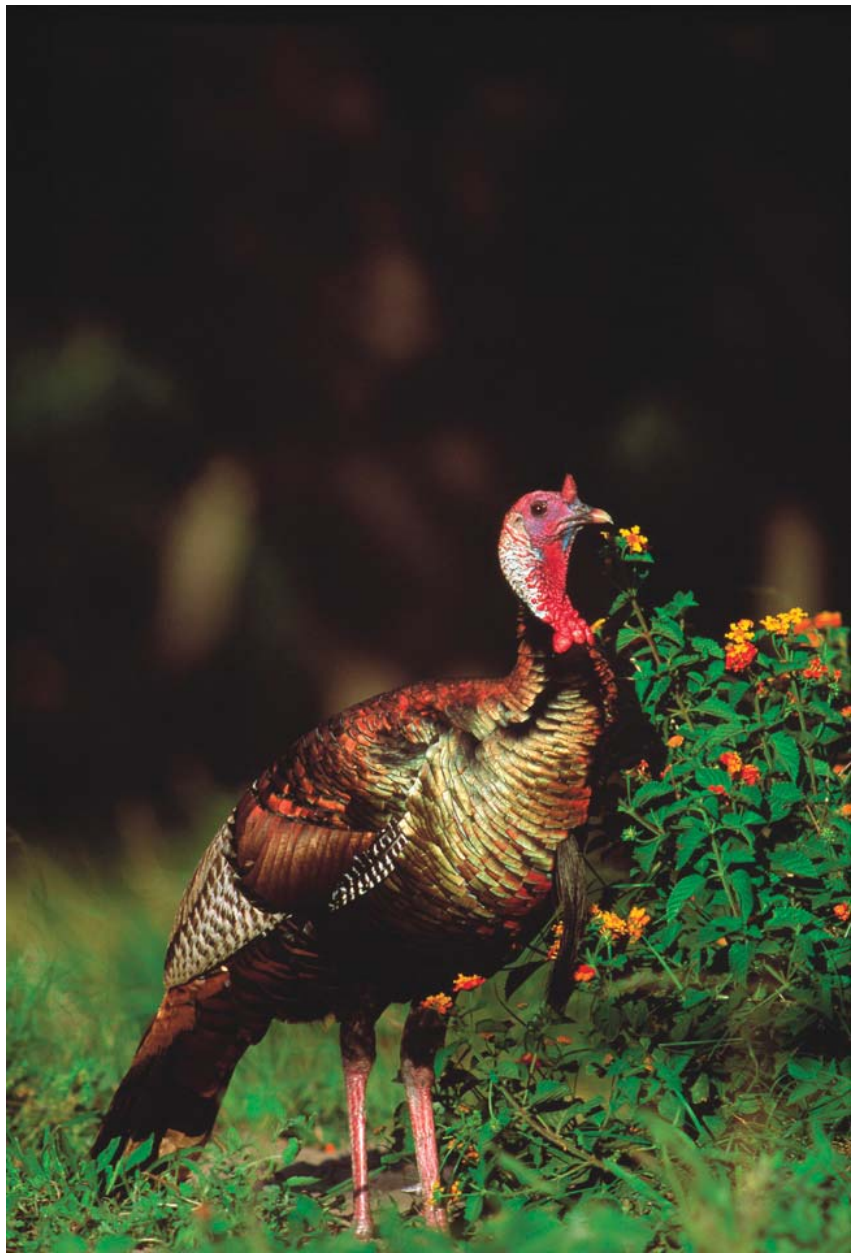

Cover is essential for wild turkey habitat to facilitate escape, nesting, and roosting. Shrubs, weeds, and grasses can all provide important cover. Turkeys prefer cover at least 18 inches in height for nesting. ${ }^{8}$ Trees are important for roosting, with low-growing brush at the base for loafing and protection while entering and leaving the roost site.

Grazing can be an important management tool for improving wild turkey habitat. In general, a light to moderate stocking rate is recommended for turkey habitat management. However, stocking rate can vary, depending on the amount of precipitation, soil type, type of vegetation, and length of the growing season. Grazing improves nesting in high rainfall areas where vegetation can become too thick. Stocking rates should be calculated annually, based on the productivity of the area and current precipitation. A deferred or rest rotation grazing system is best for turkey habitat management because it allows preferred grass, forb, and shrub plants to recuperate and prevents their degradation from overuse. One concern with grazing and turkey habitat management is nest trampling by livestock; however, this is not typically a concern unless stock density is greater than one animal unit per acre. ${ }^{9}$ 
Wild turkeys utilize riparian areas primarily in the spring and summer for nesting and foraging. Careful management of riparian areas is important in maintaining good turkey habitat. Deferred grazing of some riparian areas until 1 July will allow poults enough time to become mature and strong enough to travel. Resting at least part of a riparian area for a season also allows grasses to mature and produce seed.

Prescribed burning is also an effective tool for wild turkey habitat management. Burning can control brush encroachment as well as increase plant diversity and nutritional value. Diversity and number of insects usually increases in burned areas. Burning should occur in the fall or winter to avoid destroying nests and killing poults. A patchwork design of burned and unburned areas is desirable to provide some undisturbed cover. ${ }^{10}$

\section{Attwater's Prairie Chicken}

The Attwater's prairie chicken prefers habitat consisting of tall grass prairie with a diversity of plants and grasses of varying height. Prairie chickens need patchy open areas for nesting and foraging. A diversity of forbs is essential, as they constitute a large part of a prairie chicken's diet.

The Attwater's prairie chicken benefits from range management practices aimed at achieving and maintaining good and excellent range condition (greater than 50\% climax vegetation present). ${ }^{11}$ Cattle grazing can assist with nutrient recycling and breaking up homogeneous stands of grass. Grazing provides patchy open areas and trails where prairie chickens are known to nest. Forb diversity is also enhanced, providing a major food source for prairie chickens.

Proper stocking rate is essential for maintaining good to excellent range condition. A light to moderate grazing intensity is preferred with a utilization of no more than $50 \%$ of current year's forage growth. ${ }^{11} \mathrm{~A}$ rotational-type grazing system with periodic deferment is recommended to prevent damage to the plant community. Stocking flexibility should also be maintained to allow rapid changes in response to environmental changes such as drought.

Prescribed burning is an effective tool for managing the Attwater's prairie chicken. Burning can effectively reduce brush encroachment as well as eliminate old vegetative growth. Consequently, this opens the area for prairie chickens and creates space for new, more nutritious vegetation for livestock. Burning increases plant diversity and results in new plant growth. Burning should be completed by the end of February in occupied habitat, particularly in South Texas. ${ }^{11}$

\section{Wild Ungulates}

Wild ungulate species such as deer and elk prefer habitats with a wide range of diversity. See Table 2 for general grazing management guidelines. Livestock grazing can assist in creating and maintaining diversity. Properly managed livestock grazing can alter plant composition, increase forage
Table 2. General grazing management guidelines: wild ungulates

1. Moderate stocking rate

- $50 \%$ utilization

- Account for domestic livestock as well as wild ungulates when calculating stocking rate

2. Maintain stocking rate flexibility to respond quickly to changing conditions

3. Deferred or rest-rotation grazing system

- Gives forage species adequate time to recover

- Reduces livestock-wildlife competition for space

4. Closely monitor areas heavily used by both wild ungulates and livestock

- Riparian areas

- These sites might require a longer deferment from grazing

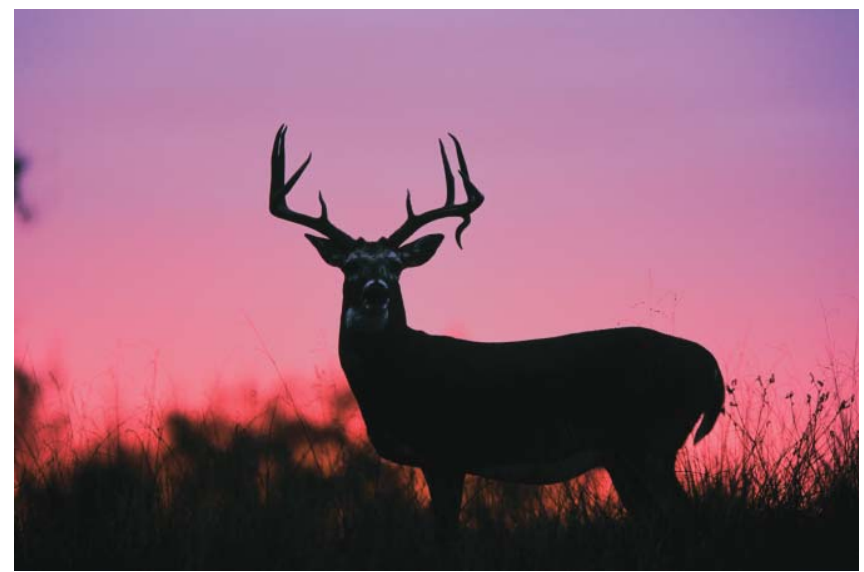

species productivity, increase forage nutritional value, and increase habitat diversity. ${ }^{12} \mathrm{~A}$ basic understanding of wild ungulate habitat requirements and the effect of grazing on that habitat is important.

\section{Deer (White-Tailed and Mule)}

Although there are differences in white-tailed and mule deer, their habitat needs and the management required to meet those needs are similar. White-tailed and mule deer are attracted to areas with a mixture of habitats such as forests, brushy areas, riparian areas, and open meadows. Each of these habitats provides an essential aspect that is important for a healthy deer population. Deer typically establish a home range and, in many cases, migrate less than two miles between summer and winter ranges. ${ }^{13}$ The size of the home range depends on the availability of the resources needed for survival. One exception is that some mule deer have been known to travel up to 50 miles between summer 
and winter ranges. Summer range is typically located in higher mountain forested areas, and winter range is located in bottomlands and sagebrush grasslands at lower elevations.

Deer utilize forbs, shrubs, and some grasses to meet their nutritional needs throughout the year. During the spring, deer consume a variety of forbs, shrubs, and some grasses. Deer usually only eat grass when it is young and succulent. During summer months when most grasses are mature, their diet consists mainly of forbs. As forbs become less available during the fall, deer include more browse in their diet. During winter months, deer consume predominately browse type vegetation. Proper management of these types of vegetation from season to season is important for maintaining deer habitat.

Cover is another essential aspect of white-tail and mule deer habitat that is important to consider. There are two basic types of deer cover: hiding or escape cover and thermal cover. Adequate hiding cover usually consists of patches of dense woody or brushy areas of 10 to 30 acres that are no more than a half mile apart. ${ }^{13}$ Thermal cover is important for helping deer maintain body temperature to conserve energy. Thermal cover protects the deer from wind and snow during the cold winter months and provides shade during summer.

Rangelands have evolved over time through a natural system of periodic grazing by wild ungulates. Completely removing this pattern of grazing can be just as harmful to deer habitat as overgrazing. Proper cattle grazing can improve forage production for white-tail and mule deer by increasing forb production through reduced competition from grass. Cattle eat primarily grass and, for the most part, do not compete with deer for forage. However, cattle and deer diet overlap can begin to increase during times of stress and when grass resources become limited. A moderate to light stocking rate may stimulate the growth of vegetative species and improve the condition of the range. When managing for wild ungulates, it is important to consider all grazing animals when calculating carrying capacity of the range. In order to keep forage production and forage consumption in balance, all animals that remove forage must be considered. As always, it is important to keep stocking rates flexible in order to quickly respond to changing conditions.

A grazing system that allows forage species to receive sufficient rest is very beneficial and has been recommended for management of deer. Such systems include short duration, high intensity-low frequency, and three- or fourpasture-one-herd grazing systems. Deer tend to occupy pastures that are periodically deferred and as deferment frequency increases, preference for that system increases. ${ }^{14}$ Continuous grazing is the least compatible grazing system for deer habitat management due to increased livestock and deer competition and potential decline in range condition.

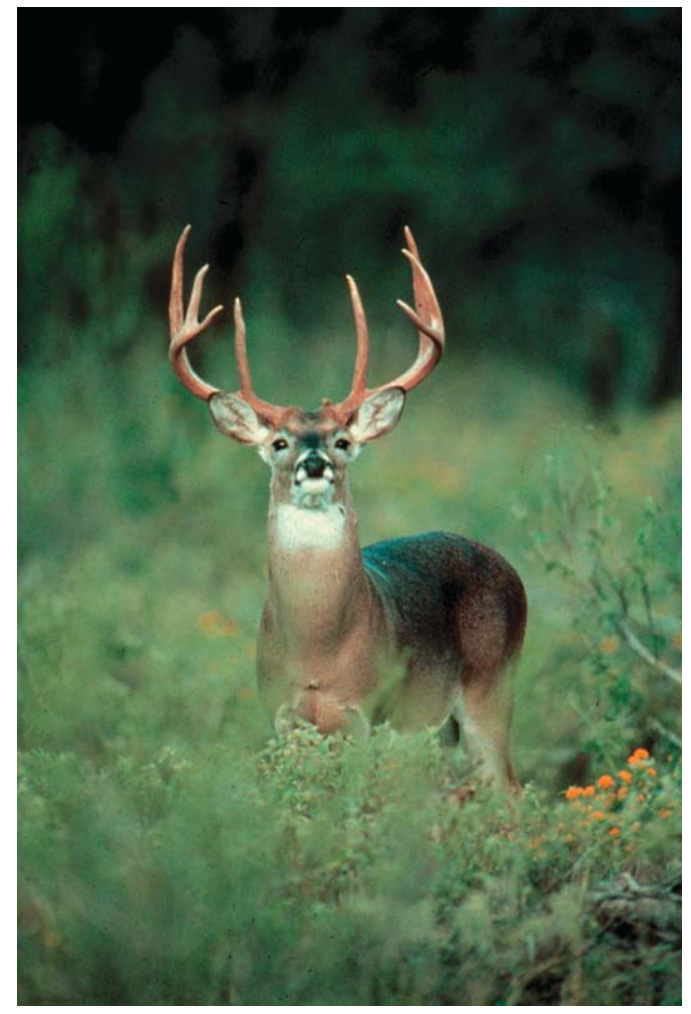

Elk

Typical elk habitat is wooded and brushy areas interspersed with large open areas. The woodland areas provide escape cover and protection from the elements whereas the open areas provide foraging opportunities. Elk usually graze in higher elevations during summer months and move to winter range at lower elevations. Elk are considered opportunistic feeders and make use of the forage that is available. Elk consume grasses, forbs, and woody plant parts or browse. In the spring and summer, elk eat mainly grasses and some early forbs. In late summer, elk consume more forbs and some browse. Fall and winter elk diets consist of dry grasses as well as forbs and some browse.

Research has shown that cattle grazing can create conditions that are beneficial to elk. These improved conditions are created when cattle remove dead, unpalatable material that allows more nutritious forage plants to grow. Elk select green vegetative grasses in the spring, forbs in the summer, and avoid areas where dead plant material is present. ${ }^{15}$ A study in Wyoming showed that during spring, fall, and winter, elk preferred to graze in areas cattle had grazed the summer before. ${ }^{16}$ Another Oregon study concluded that well-managed grazing during late spring can improve the quality of bluebunch wheatgrass and Idaho fescue for elk grazing winter range. ${ }^{17}$

As with the other wildlife species, a light to moderate stocking rate is best when managing for both livestock and elk. One exception could be during fall grazing to improve 
spring and summer forage for elk. One study concluded that a $70 \%$ utilization treatment resulted in the greatest increase in forage availability. ${ }^{15}$ However, the authors did not recommend this high utilization rate for key winter range areas. High spring use of intensely fall grazed areas by elk and deer would require additional management. A deferred or rest-rotational grazing system is recommended over a continuous grazing system because of decreased elk and livestock interactions and because it provides key forage species an opportunity to recover after grazing.

\section{Synergistic Benefits of Dual-Purpose Management}

Perhaps one of the greatest advantages of dual management for both cattle and wildlife is the amplified benefits or effects of these activities. Management for both livestock and wildlife can yield greater financial returns than either by itself. Dual purpose management can increase returns to management activities that many producers already practice. One example of such a practice is the development of water resources. The distribution and productivity of both cattle and wildlife are enhanced by the increased availability of surface water. Providing nutritional supplements to cattle to improve performance and forage utilization (salt, minerals, and protein) can benefit many species of wildlife as well. Maintaining or improving range resources and condition is a practice beneficial to both cattle and wildlife. For example, prescribed burning improves vegetation composition and structure for wildlife while improving forage production and nutrition for cattle.

The public perception of ranching, especially on public lands, is becoming more and more important. An unexpected benefit of actively managing for both livestock and wildlife is that when the public understands that ranchers make management decisions that benefit wildlife and wildlife habitat, it can have a more favorable view of ranching and livestock production. These are only a few of the many management practices that benefit both cattle and wildlife. It is important that managers identify those activities that are most beneficial to their specific operations and incorporate them into their strategic management plan.

\section{Summary and Concluding Thoughts}

Managing rangeland for the benefit of both wildlife and livestock is an achievable strategy for ranchers and other rangeland managers. Although specific tactics vary depending on the wildlife species, flexible stocking rates, flexible grazing systems, patch burning, adequate water, and protecting environmentally sensitive areas are some of the management practices that generally provide adequate habitat for many wildlife species. These approaches also have proven successful and are widely recommended by rangeland management professionals for successful grazing livestock management.
The resulting opportunity for deriving income from managing rangelands for both livestock and wildlife is currently providing ranchers with an opportunity to diversify sources of income. This strategy can also reduce risk in the dynamic and volatile marketplace that ranchers find themselves. Downsides of this strategy are difficult to identify. The upside is exciting.

\section{References}

1. Stegner, W. 1992. Beyond the hundredth meridian. New York, NY, USA: Penguin Books. 438 p.

2. Forgason, C. A., And T. E. Fulbright. 2003. Cattle, wildlife, and range management on King Ranch over the years. In C. A. Forgason, F. C. Bryant, and P. Genho [EDs.]. Ranch management: integrating cattle, wildlife, and range. Kingsville, TX, USA: King Ranch. p. 9-21.

3. Crawford, J. A., R. A. Olson, N. E. West, J. C. Mosley, M. A. Schroeder, T. D. Whitson, R. F. Miller, M. A. GregG, And C. S. Boyd. 2004. Synthesis paper: ecology and management of sage-grouse and sage-grouse habitat. Journal of Range Management 57:2-19.

4. Adams, B. W., J. Carlson, D. Milner, T. Hood, B. Cairns, And P. Herzog. 2004. Beneficial grazing management practices for sage-grouse (Centrocercus Urophasianus) and ecology of silver sagebrush (Artemisia cana) in southeastern Alberta. Lethbridge, Alberta, Canada: Technical Report, Public Lands and Forests Division, Alberta Sustainable Resource Development. Pub. No. T/049. 60 p.

5. Hanselka, C. W., and F. S. Guthery. Bobwhite quail management in south Texas. College Station, TX, USA: Texas Agricultural Extension Service. 8 p.

6. Wilkins, R. N., And W. G. Swank. 1992. Bobwhite habitat use under short duration and deferred-rotation grazing. Journal of Range Management 45:549-553.

7. Hammerquist-Wilson, M. M., and J. A. Crawford. 1981. Response of bobwhites to cover changes within three grazing systems. Journal of Range Management 41:213-218.

8. Litton, G. W., And F. Harwell. 1995. Rio Grande turkey habitat management. Austin, TX, USA: Texas Parks and Wildlife: Wildlife Division. $13 \mathrm{p}$.

9. Lyons, R. K., and B. D. Wright. 2003. Using livestock to manage wildlife habitat. College Station, TX, USA: Texas Cooperative Extension. B-6136. 6 p.

10. Cathey, J. C., K. Melton, J. Dreibelbis, B. Cavney, S. L. Locke, S. J. DeMaso, and B. Collier. 2007. Rio Grande wild turkey in Texas: biology and management. College Station, TX, USA: Texas Cooperative Extension. B-6198. $14 \mathrm{p}$.

11. Campbell, L., and B. Armstrong. 1997. Managing brush and maintaining habitat for endangered species. Proceedings of a Conference on Brush Sculptors: Innovations For Tailoring Brushy Rangelands to Enhance Wildlife Habitat and Recreational Value; 21-22 August, 17-18 September 1997; Uvalde, TX, USA. Session III. 9 p.

12. VAVRA, M. 2005. Livestock grazing and wildlife: developing compatibilities. Rangeland Ecology छ Management 58: 128-134.

13. Olson, R. 1992. White-tailed deer habitat requirements and management in Wyoming. Laramie, WY, USA: Department of Renewable Resources, College of Agriculture, University of Wyoming. B-964. 19 p. 
14. Reardon, P. O., L. B. Merrill, and C. A. Taylor, Jr. 1978. White-tailed deer preferences and hunter success under various grazing systems. Journal of Range Management 31:40-42.

15. Short, J. J., And J. E. Knight. 2003. Fall grazing affects big game forage on rough fescue grasslands. Journal of Range Management 56:213-217.

16. Crane, K. K., J. C. Mosley, T. K. Brewer, W.L.F. Torstenson, and M. W. Tess. 2001. Influence of cattle grazing on elk habitat selection. Proceedings of the Western Section of the American Society of Animal Science; 20-23 June 2001; Bozeman, MT, USA. 5 p.
17. Clark, P. E., W. C. Krueger, L. D. Bryant, and D. R. Thomas. 2000. Livestock grazing effects on forage quality of elk winter range. Journal of Range Management 53:97-105.

Authors are Graduate Fellow, King Ranch Institute for Ranch Management, Texas AEऽM University-Kingsville, Kingsville, TX 78363, USA, ksaha01@tamuk.edn (Anderson); and Assistant Professor, King Ranch Institute for Ranch Management, Texas AEऽM University-Kingsville, Kingsville, TX 78363, USA (McCuistion).

\section{Interpreting and Measuring Indicators of Rangeland Health}

\section{3-16 May: Las Cruces, New Mexico BLM Course 10-13 June: Worland, Wyoming}

Content (50\% field, same for both sessions, Tuesday 8:00 AM - Friday 12:00 PM): application of Interpreting Indicators of Rangeland Health, reference sheet development, ecological site identification, and supplementary quantitative measurements

Instructors: Fee Busby (Utah State), Jeff Herrick (ARS), Mike Pellant (BLM), Dave Pyke (USGS), and Pat Shaver (NRCS)

Registration (required, no cost): DOI employees: https://doilearn.doi.gov/; others: http://doilearn.doi.gov

Related course at IGC-IRC, Inner Mongolia, China (fee applies): Inventory, Assessment, and Monitoring of the Ecological Status of Rangelands: A Practical Approach 24-28 June 2008

Registration instructions and more information for all three courses: http://usda-ars.nmsu.edu/JER/Monit_ Assess/monitoring.htm > Courses

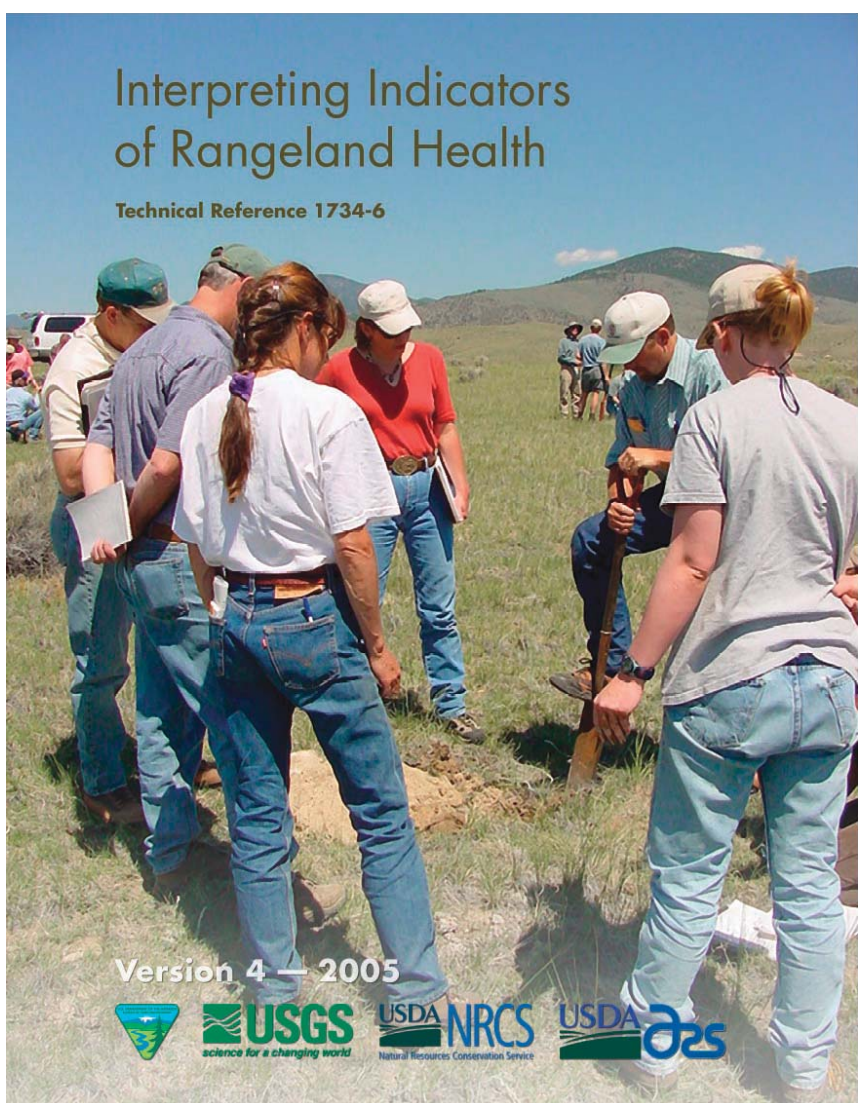

